\title{
Left main aneurysm and what's next?
}

\author{
Krzysztof Ściborski ${ }^{1}$ Konrad Kaaz², Donald Drożdż, Marta Negrusz-Kawecka², Andrzej Mysiak²
}

${ }^{1}$ Department of Cardiology, University Hospital, Wroclaw, Poland

${ }^{2}$ Department of Cardiology, Medical University of Wroclaw, Poland

Postep Kardiol Inter 2014; 10, 1 (35): 57-59

DOI:10.5114/pwki.2014.41473

\begin{abstract}
The purpose of the case report is to present a case of a 65 -year-old male, referred for coronary angiography because of a typical chest pain. The coronary angiography showed an aneurysm of the left main coronary artery. Despite the absence of obvious ischemic symptoms and because of the potential complications of the aneurysm with a width of $15 \mathrm{~mm}$, the patient underwent surgery.
\end{abstract}

Key words: left main coronary artery aneurysm.

\section{Introduction}

Coronary artery aneurysm is a rare disorder. It is diagnosed when the diameter of the vessel is at least 1.5 times that of a normal coronary artery. In the population the incidence of left main coronary artery (LMA) is approximately $0.1 \%$ of cases. The major cause of LMA in adults is atherosclerosis [1]. Other causes are inflammation, cocaine intoxication, trauma (associated with resuscitation), and iatrogenic effects (angioplasty, surgery of the ascending aorta) [2-6]. The LMA in children is often found in Kawasaki or Takayasu disease. It may also be associated with other cardiac defects such as postponement of the main arteries, or tetralogy of Fallot [7, 8]. A definitive diagnosis can rarely be made.

The LMA is associated with serious complications such as vessel dissection, rupture, or myocardial infarction, which can lead to sudden cardiac death [9, 10]. There is no officially sanctioned treatment for this disease and all existing knowledge about it can be gained from case reports mainly. The primary treatment in children and adults is a surgical procedure [11]. The first case reports about coronary artery bypass graft (CABG) in LMA can be found in the 1970s [12]. Currently, several types of treatment, such as surgical removal of the aneurysm and CABG, or isolated CABG, stent graft or coil can be applied [13-17]. A lack of surgical standards triggers the need to search for new methods such as removal of the aneurysm and replacement with a new artery or wire [18-20].
When choosing treatment one can also stick to a conservative approach [21].

\section{Case report}

The aforementioned 64-year-old male, with a past history of myocardial infarction of the inferior wall 13 years ago, hypertension, and obesity (body mass index (BMI) $37 \mathrm{~kg} / \mathrm{m}^{2}$ ), was referred to the Cardiology Clinic because of a typical chest pain. Echocardiography showed enlarged left heart (LV: 62/45 mm, LA: $44 \mathrm{~mm}$ ), multi-segment wall motion abnormalities with decreased left ventricular ejection fraction (EF: 32\%) and moderate mitral regurgitation. Coronary angiography confirmed amputation of the proximal segment of the right coronary artery (RCA) with proper filling of the circuit and the LMA with a diameter of $15 \mathrm{~mm}$ (Figures $1 \mathrm{~A}$ and $1 \mathrm{~B}$ ) and turbulent blood flow. The patient was in functional class NYHA II. The surgical decision on the need for operative intervention was based on the ischemic symptoms. In order to highlight the degree of severity of the abnormal flow through the aneurysm we used the fractional flow reserve (FFR) technique which, however, showed no loss of value. After consulting another medical centre the patient was qualified for surgery. Afterwards, mitral valve plasty was performed, a venous bypass was implanted in the RCA, and the LMA was excised with uniting of the left anterior descending artery (LAD), circumflex artery (Cx) and intermediate artery (IM) with a short venous bypass.

\section{Corresponding author:}

Konrad Kaaz MD, PhD, Department of Cardiology, Medical University of Wroclaw, 213 Borowska St, 50-566 Wrocław, Poland, phone: +48 6915236 14, e-mail: konrad.kaaz@gmail.com

Received: 17.11.2013, accepted: 9.01.2014. 


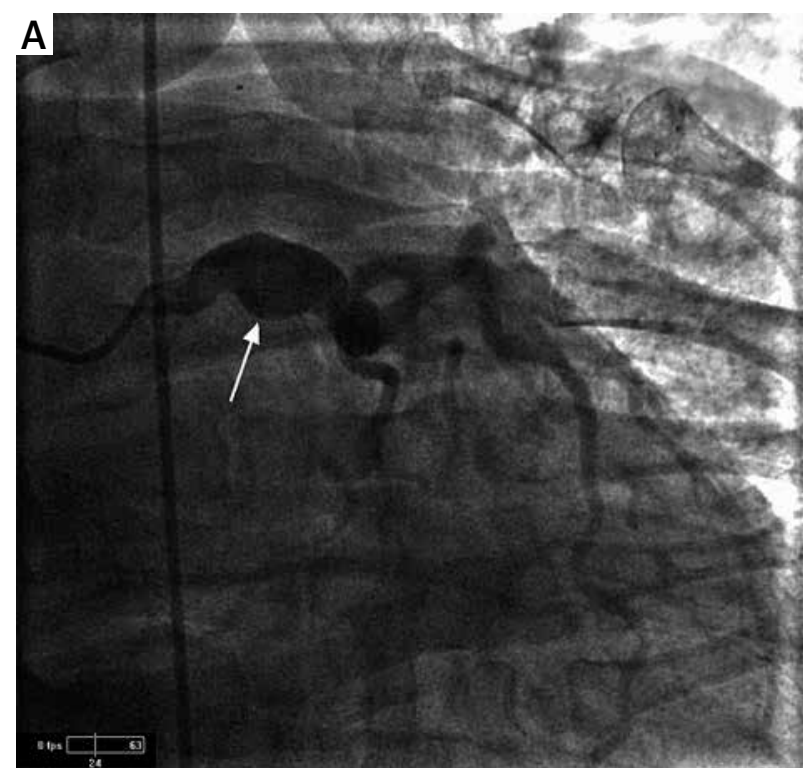

Figure 1. Coronary angiography - left main aneurysm

The patient underwent surgery which gave him complete revascularization, correction of mitral valve disease, and removed the risk of rupture or clotting of the aneurysm and a secondary heart attack connected with death which was, from our point of view, the most crucial.

\section{Discussion}

In no other field of medicine, except cardiology, have there been so many standards and guidelines of conduct. Nevertheless, there are still some disease entities with no treatment procedures formally approved. These include the rare LMA. It seems that invasive treatment may improve prognosis in this disease, but there has been no conclusive evidence for it. The question is whether cardiac surgery (involving thoracotomy and extracorporeal circulation) with its potential complications is superior to conservative treatment in a case of asymptomatic pathology [22].

\section{References}

1. Garg N, Moorthy N. Left main coronary artery aneurysm: an uncommon aetiology for myocardial infarction in the young. Cardiol Young 2010; 20: 584-586.

2. Tizón-Marcos H, Bagur R, Bilodeau S, et al. Left main mycotic aneurysm causing myocardial infarction. Can J Cardiol 2010; 26: e276-e277.

3. Kalavrouziotis D, Dagenais F. Giant mycotic pseudoaneurysm of the left main coronary artery after pneumococcal pneumonia. J Thorac Cardiovasc Surg 2010; 140: e50-e52.

4. Leguerrier A, Bercot M, Piwnica A. Aneurysm of the main stem of the left coronary artery associated with aortic insufficiency and aneurysm of the ascending aorta. Report of a case with successful surgical repair. Thorax 1978; 33: 649-652.

5. Gallo MM, Carrizo S, Cooke RS, et al. Post-traumatic false (pseudo) aneurysm of the left main coronary artery. Medicina (B Aires) 2011; 71: 373-375.

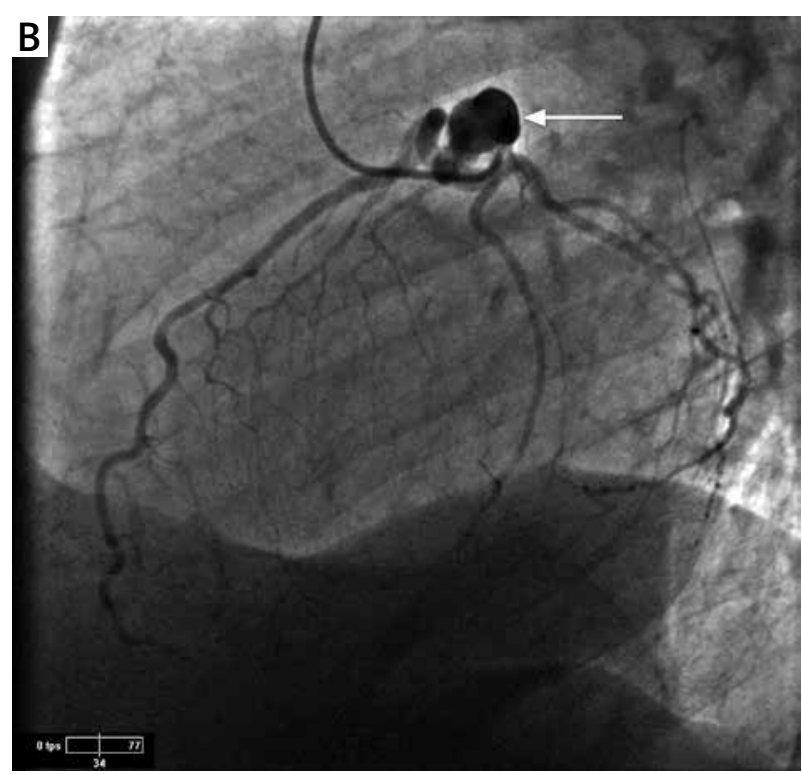

6. Ngaage DL, Singh SK, Bresnahan JF, et al. Chronic traumatic aneurysm of the left main coronary artery causing myocardial infarction. Ann Thorac Surg 2005; 80: 2383.

7. Dundar C, Tigen K, Pala S, et al. Congenital left main coronary artery aneurysm. Cardiol J 2011; 18: 430-433.

8. Salamat M, Khan MS. Ring-calcification of giant coronary artery aneurysm of an 11-year-old child with history of kawasaki disease. Pediatr Cardiol 2010; 31: 558-559.

9. Karabulut A, Tanriverdi S. Progression of a small eccentric aneurysm to spontaneous coronary dissection within the left main coronary artery. Kardiol Pol 2010; 68: 1404-1406.

10. Tizón-Marcos H, Bagur R, Bilodeau S, et al. Left main mycotic aneurysm causing myocardial infarction. Can J Cardiol 2010; 26 : e276-e277.

11. Sandiford FM, Vargo TA, Shih JY, et al. Successful triple coronary artery bypass in a child with multiple coronary aneurysms due to Kawasaki's disease. J Thorac Cardiovasc Surg 1980; 79: 283-287.

12. Moses HW, Huddle RA Jr, Nanda NC, et al. Surgical management of an aneurysm of the left main coronary artery. Ann Thorac Surg 1979; 27; 569-573.

13. Saccà S, Pacchioni A, Nikas D. Coil embolization for distal left main aneurysm: a new approach to coronary artery aneurysm treatment. Catheter Cardiovasc Interv 2012; 79: 1000-1003.

14. Nakayama Y, Shikawa A, Ayusawa Y, et al. Surgical repair of complicated coronary arteriovenous fistula and coronary artery aneurysm in an elderly patient after 26 years of conservative therapy. Heart Vessels 2011; 26: 111-116.

15. Mavroudis C, Dodge-Khatami A, Stewart RD, et al. An overview of surgery options for congenital coronary artery anomalies. Future Cardiol 2010; 6: 627-645.

16. Eltahawy EA, Colyer WR Jr. Left main coronary artery aneurysm and associated left anterior descending coronary artery stenosis treated with a stent graft. J Invasive Cardiol 2009; 21: E126-E127.

17. Agarwal R, Jeevanandam V, Jolly N. Surgical treatment of a giant coronary artery aneurysm: a modified approach. Ann Thorac Surg 2007; 84: 1392-1394. 
18. Matsubayashi K, Asai T, Nishimura O, et al. Giant coronary artery aneurysm in the left main coronary artery: a novel surgical procedure. Ann Thorac Surg 2008; 85: 2130-2132.

19. Christiansen S, Klocke A, Hoffman A, Autschbach R. Surgical management of a left main stem coronary artery aneurysm. J Card Surg 2008; 23: 69-70.

20. Bruhin R, Stock UA, Breuer M, Wahlers T. Successful in situ repair of a symptomatic left main coronary artery aneurysm by a saphenous vein graft. Interact Cardiovasc Thorac Surg 2004; 3: 434-436.

21. Dhakam S, Ahmed H, Jafferani A. Percutaneous coronary intervention of left main pseudoaneurysm with customized covered stents. Catheter Cardiovasc Interv 2011 ; 77: 1033-1035.

22. FitzGibbon GM, Keon WJ, Burton JR. Aorta-coronary bypass in patients with coronary artery disease who do not have angina. J Thorac Cardiovasc Surg 1984; 87: 717-724. 